\title{
Analysis of 153 cases of odontogenic cysts in a South Indian sample population: a retrospective study over a decade
}

\section{Manickam Selvamani \\ Mandana Donoghue \\ Praveen Shivappa Basandi}

Department of Oral and Maxillofacial Pathology \& Microbiology, College of Dental Sciences \& Hospital, Davangere, Karnataka, India.
Declaration of Interests: The authors certify that they have no commercial or associative interest that represents a conflict of interest in connection with the manuscript.

Corresponding author:

Manickam Selvamani

E-mail:selvamani.mds@gmail.com

Received for publication on Nov 15, 2011 Accepted for publication on Apr 17, 2012

\begin{abstract}
The purpose of this study was to determine the prevalence of odontogenic cysts and to identify their clinico-pathological features among patients by studying biopsy specimens obtained from the archives of the Department of Oral and Maxillofacial Pathology, College of Dental Sciences, Davangere, Karnataka, India, during the past 10 years. Data for the study were retrieved from the case records of patients fitting the histological classification of the World Health Organization (1992). Analyzed clinical variables included age, gender, anatomical location, and histological diagnosis. Of the 2275 biopsy reports analyzed, 194 cases $(8.5 \%)$ were jaw cysts, including odontogenic $(6.7 \%)$ and nonodontogenic cysts $(0.25 \%)$. Odontogenic cysts included $69.3 \%$ radicular, $20.3 \%$ dentigerous, $5.2 \%$ keratinizing odontogenic, 3.3\% residual, and 1.9\% other cysts, such as lateral periodontal, botryoid odontogenic, and gingival cysts. The most frequent clinical manifestation was swelling, followed by a combination of pain and swelling. Age, gender, and location were related to the etiopathologic characteristics of the cyst type. A definitive diagnosis can be made on the basis of clinical, radiological, and histological findings, which makes a good interdepartmental relationship between the clinicians and pathologists essential. Knowledge of the biological and histological behavior of the odontogenic cysts is required for their early detection and treatment.
\end{abstract}

Descriptors: World Health Organization; Odontogenic Cysts; Nonodontogenic Cysts.

\section{Introduction}

Odontogenic cysts are frequently encountered in dental practice and constitute an important aspect of oral and maxillofacial pathology. An odontogenic cyst is formed by activation of odontogenic cell rests entrapped within the bone tissue or gingival tissue of the jaws, such as the epithelial remains of Malassez, the dental lamina (cell rests of Serres), or the enamel organ. Inflammatory odontogenic cysts are formed due to activation of these cell rests by an inflammatory process. ${ }^{1}$ Developmental and inflammatory odontogenic cysts are epithelial in origin, exhibiting slow growth and a tendency towards expansion. However, despite their benign biological behavior, these lesions can reach a marked size if they 
are not diagnosed quickly and treated appropriately. ${ }^{2}$ Therefore, their correct diagnosis is essential for prompt and appropriate surgical treatment and adequate follow-up.

Despite the large number of studies on odontogenic cysts in the literature, information regarding the demographic profile of these lesions in different populations is limited, especially in the Indian population. Thus, the objective of the present study is to determine the distribution of odontogenic cysts diagnosed histologically over a period of 10 years in Davangere and the surrounding districts of Karnataka, India.

\section{Methodology}

A retrospective study on odontogenic cysts was conducted on the basis of oral biopsy specimens retrieved from the archives of the Department of Oral and Maxillofacial Pathology, College of Dental Sciences, Davangere, India, available from the year 2001 through December 2010. The age, gender, and anatomical location of all cases were compiled from the clinical data sent together with the biopsy records. Histopathology slides stained with hematoxylin and eosin were selected and re-evaluated according to the current concepts outlined by the World Health Organization. ${ }^{3}$

Inclusion criteria involved the histological confirmation of odontogenic cysts. Lesions with histological findings that were not compatible with odontogenic cysts were excluded from the study. Some records that were sent with the biopsy material were incomplete and were excluded. The following variables were recorded:

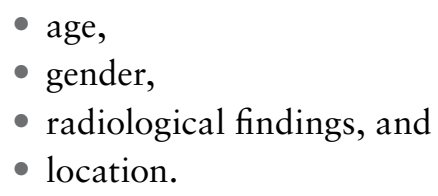

The following anatomical sites were defined:

- anterior,

- posterior, and

- anterio-posterior segments in both the maxilla and mandible.

The anterior region was defined as the canine-to- canine segment. The posterior region was defined as the premolar and molar region, including the ramus of the mandible. The anterior-posterior segment was defined as involving both the anterior and posterior segments.

Data were subjected to descriptive statistical analyses with the SPSS version 16.0 statistical software package (SPSS Inc., Chicago, USA).

\section{Results \\ Prevalence rate}

Among the 2275 oral biopsy specimens retrieved, we found 194 cases $(8.5 \%)$ of jaw cysts, including 153 cases $(6.7 \%)$ of odontogenic cysts and 5 cases $(0.25 \%)$ of nonodontogenic cysts. To guarantee the most reliable epidemiologic profile for the odontogenic cysts, nonodontogenic cysts were separated from analysis. Individual analysis on the odontogenic cysts showed that these included 106 cases $(69.3 \%)$ of radicular, 31 cases $(20.3 \%)$ of dentigerous, 8 cases $(5.2 \%)$ of keratinizing odontogenic (KOC), 5 cases $(3.3 \%)$ of residual, and 3 cases $(1.9 \%)$ of other cysts, such as lateral periodontal, botryoid odontogenic, and gingival cysts (Table 1).

\section{Age and gender}

Of all of the odontogenic cysts, 84 cases $(55 \%)$ were observed in men and 69 cases $(45 \%)$ were seen in women, with a male: female ratio of 1.2:1. The mean age was 28 years (range: 6-84 years), with 52 cases $(33.9 \%)$ and 42 cases $(27.4 \%)$ being diagnosed in the second and third decades of life, respectively. Correlation analyses revealed that radicular cysts were most frequently seen in the second and third decades, dentigerous cysts in the second decade, and KOCs in the third decade of life (Table 2).

\section{Location}

Of the 153 cysts, 88 cysts $(57.5 \%)$ were on the maxilla and 65 cysts $(42.5 \%)$ were on the mandible. In the maxilla, the most commonly affected site was the anterior region (82 cysts, 53.6\%), whereas the most common site in the mandible was the posterior region (48 cysts, 31.4\%). The most frequent locations for inflammatory cysts (radicular or residual cysts) were the anterior maxilla (59 cysts, 53.2\%) 
Table 1 - Prevalence of odontogenic cysts according to age.

\begin{tabular}{|c|c|c|c|c|c|c|c|c|}
\hline \multirow{2}{*}{ Age } & \multirow{2}{*}{ Number } & \multicolumn{5}{|c|}{ Developmental cyst } & \multicolumn{2}{|c|}{ Inflammatory cyst } \\
\hline & & DC & $\mathrm{KOC}$ & GC & $\mathrm{BOC}$ & LPC & $\operatorname{RadC}$ & $\operatorname{Res} C$ \\
\hline $0-10$ & 14 & 8 & - & - & - & - & 6 & - \\
\hline $11-20$ & 52 & 11 & 1 & 1 & - & - & 39 & - \\
\hline $21-30$ & 42 & 3 & 6 & - & - & 1 & 31 & 1 \\
\hline $31-40$ & 21 & 6 & - & - & 1 & - & 13 & 1 \\
\hline $41-50$ & 16 & 1 & 1 & - & - & - & 13 & 1 \\
\hline $51-60$ & 2 & - & - & - & - & - & 1 & 1 \\
\hline $61-70$ & 4 & 2 & - & - & - & - & 1 & 1 \\
\hline $71-80$ & 1 & - & - & - & - & - & 1 & - \\
\hline $80-90$ & 1 & - & - & - & - & - & 1 & - \\
\hline Total & 153 & 31 & 8 & 1 & 1 & 1 & 106 & 5 \\
\hline
\end{tabular}

Data are reported as numbers. DC, dentigerous cyst; KOC, keratinizing odontogenic cyst; $G C$, gingival cyst; $\mathrm{BOC}$, botryoid odontogenic cyst; LPC, lateral periodontal cyst; RadC, radicular cyst; and ResC, residual cyst.

and the posterior mandible (39 cysts, $35.1 \%$ ). Dentigerous cysts were most commonly seen in the anterior maxilla ( 20 cysts, $64.5 \%$ ), whereas KOCs were most common in the mandible (Table 3 ).

The most common clinical manifestation was swelling with or without pain. Most cases, especially of developmental origin, were discovered through radiographs.

\section{Discussion}

According to previous studies, ${ }^{4-6}$ odontogenic cysts are diagnosed in $7 \%$ to $12 \%$ of all oral and maxillofacial biopsies, consistent with the prevalence rate obtained here $(6.7 \%)$. Our results may have been influenced by our redefinition of odontogenic keratocysts as keratocystic odontogenic tumors, which has an impact in terms of the frequency rate of odontogenic cyst diagnosis. Overall, cysts occurred more frequently in adult men than in women, in agreement with findings reported in other studies. ${ }^{5,6}$ The maxilla was most commonly affected by odontogenic cysts, which is in conflict with the findings of Meningaud et al. ${ }^{7}$ and Koseoglu et al. ${ }^{8}$ but consistent with those of other studies. ${ }^{2,6,9}$ Although the cysts showed a predilection for the maxilla, the posterior mandibular region was also a common site.

Inflammatory jaw cysts include lesions that arise as a result of epithelial proliferation within an in-
Table 2 - Distribution of odontogenic cysts according to gender.

\begin{tabular}{|c|c|c|c|c|}
\hline & Total & Male & Female & $M: F$ \\
\hline DC & $31 \quad$ (20.3) & $23 \quad(74.2)$ & $8(25.8)$ & $2.9: 1$ \\
\hline $\mathrm{KOC}$ & $8 \quad(5.2)$ & $5 \quad(62.5)$ & 3 (37.8) & $1.7: 1$ \\
\hline LPC & $1 \quad(0.7)$ & $1(100)$ & - & 1 \\
\hline $\mathrm{BOC}$ & $1 \quad(0.7)$ & $1(100)$ & - & 1 \\
\hline GC & $1 \quad(0.7)$ & - & $1 \quad(0.7)$ & $0: 1$ \\
\hline $\operatorname{RadC}$ & $106 \quad(69.3)$ & $50 \quad(47.2)$ & $56(52.8)$ & 0.9:1 \\
\hline $\operatorname{Res} C$ & $5 \quad$ (3.3) & $4 \quad(80)$ & 1 (20) & 4:01 \\
\hline TOTAL & $153(100)$ & $84 \quad(55)$ & 69 (45) & \\
\hline
\end{tabular}

Data are shown as $\mathrm{n}(\%)$ or ratio. DC, dentigerous cyst; $\mathrm{KOC}$, keratinizing odontogenic cyst; LPC, lateral periodontal cyst; BOC, botryoid odontogenic cyst; GC, gingival cyst; RadC, radicular cyst; and ResC, residual cyst.

flammatory focus, especially due to pulpal infection after dental caries. The radicular cyst, also known as the periapical cyst, is the most common inflammatory cyst. It arises from epithelial residues in periapical periodontitis after death and necrosis of the pulp. Radicular cysts represented $69.3 \%$ of all cysts in our study, similar to the findings of Procket et al. ${ }^{6}(72.5 \%)$ and Jones et al. ${ }^{10}(60.3 \%)$ but higher than the findings of Manor et al. ${ }^{11}$ (48\%), Meningaud et al. ${ }^{7}$ (53.5\%), and Koseoglu et al. ${ }^{8}$ (56.9\%). Female predilection $(52.8 \%)$ was slightly greater than in males $(47.2 \%)$, consistent with some previous studies ${ }^{2,4-6}$ but different from others. ${ }^{7,810}$ In the 
Table 3 - Distribution of odontogenic cysts according to anatomical site.

\begin{tabular}{|c|c|c|c|c|c|c|c|}
\hline & \multicolumn{3}{|c|}{ Maxillary jaw } & \multicolumn{3}{|c|}{ Mandibuar jaw } & \multirow[b]{2}{*}{ TOTAL } \\
\hline & ANT & POS & ANT-POS & ANT & POS & ANT-POS & \\
\hline DC & $20 \quad(64.5)$ & - & $1 \quad(3.2)$ & $5(16.1)$ & $5(16.1)$ & - & $31(100)$ \\
\hline $\mathrm{KOC}$ & $2 \quad(25)$ & - & - & $1(12.5)$ & 3 (37.5) & $2(25)$ & $8(100)$ \\
\hline LPC & - & - & - & - & $1(100)$ & - & $1(100)$ \\
\hline $\mathrm{BOC}$ & - & - & $1(100)$ & - & - & - & $1(100)$ \\
\hline GC & $1(100)$ & - & - & - & - & - & $1(100)$ \\
\hline $\operatorname{RadC}$ & $59 \quad(55.7)$ & $3(2.8)$ & - & $9 \quad(8.5)$ & 35 (33) & - & $106(100)$ \\
\hline $\operatorname{Res} C$ & - & $1(20)$ & - & - & $4(80)$ & - & $5(100)$ \\
\hline Developmental cysts & $23 \quad(54.8)$ & - & $2 \quad(4.8)$ & $6(14.3)$ & 9 (21.3) & $(4.8)$ & $42(100)$ \\
\hline Inflammatory cysts & $59 \quad(53.2)$ & $4 \quad(3.6)$ & - & $9 \quad(8.1)$ & 39 (35.1) & - & $111(100)$ \\
\hline Total & 82 (53.6) & $4(2.6)$ & (1.3) & 15 (9.8) & $48 \quad(31.4)$ & 2 (1.3) & $153(100)$ \\
\hline
\end{tabular}

Data are shown as $\mathrm{n}(\%)$. DC, dentigerous cyst; KOC, keratinizing odontogenic cyst; LPC, lateral periodontal cyst; BOC, botryoid odontogenic cyst; GC, gingival cyst; RadC, radicular cyst; ResC, residual cyst; ANT, anterior; POS, posterior; ANT-POS, anterior-posterior.

latter cases, the higher prevalence in males may be explained by the fact that males are more likely to sustain trauma. Similar to many previous findings, we observed that the most frequently affected site was the anterior maxilla. ${ }^{2,5,6,8,10}$ Of note, the results of Meningaud et al. ${ }^{7}$ differ in this regard. Radicular cysts were more common in the second and third decades of life, consistent with the findings of Souza et al. ${ }^{12}$

The dentigerous cyst is a developmental cyst that encloses the crown of an unerupted tooth by expansion of its follicle and is attached to its neck. It is the second-most common odontogenic cyst, with a frequency ranging from $11.4 \%$ to $44 \% .^{5-7,10-}$ ${ }^{14}$ We observed that $20.3 \%$ of cases were dentigerous cysts, most of which were diagnosed in males, consistent with all ${ }^{10,13,15,16}$ but one previous study. ${ }^{6}$ The posterior mandibular region is a common site of the lesion, followed by the anterior maxilla, coinciding with our results. According to Jones et al., ${ }^{10}$ the frequency of dentigerous cysts at these sites can be explained by the fact that the lower third molars and upper canines are the most commonly impacted teeth. Most dentigerous cysts are diagnosed between the first and second decades of life, ${ }^{2,5,8,12}$ consistent with the results in the present study, although Jones et al. ${ }^{10}$ reported a peak incidence between the fifth and sixth decades.
Odontogenic keratocyst $(\mathrm{OKC})$ is the third most common type of odontogenic cyst. The OKC arises from the remnants of the dental lamina. It is known for its uniquely aggressive clinical behavior, marked tendency to recur, high mitotic count, and greater epithelial turnover rate. In 2005, the $\mathrm{WHO}^{17}$ issued a new classification for odontogenic tumors, dividing the entity previously known as OKC into 2 subtypes:

- "keratocystic odontogenic tumor" (KOT) containing parakeratinized epithelium and

- KOC containing orthokeratinized epithelium.

The KOC has a slight male predilection and favors the posterior mandible.

A lateral periodontal cyst occurs lateral to the root of a vital tooth. They often do not cause clinical signs or symptoms and, thus, are usually found in routine radiographic examinations. Polycystic lesions are called botryoid odontogenic cysts, due to their resemblance to a cluster of grapes. Studies in the literature have found a frequency of $0.3 \%$ to $0.8 \%$ among all odontogenic cysts. ${ }^{2,47,10}$ We found a single case $(0.5 \%$ incidence) of each type. Gingival cysts are relatively uncommon lesions that may arise due to traumatic implantation of the surface epithelium or from the cystic degeneration of deep projections of the surface epithelium, remnants of the 
dental lamina, enamel organ, or cell rests of Malassez. ${ }^{18}$ We observed 1 case of a gingival cyst $(0.5 \%)$, consistent with the results of Daley et al. $(0.4 \%){ }^{19}$ Female predilection was seen, as was also the case in the study of Jones et al. ${ }^{10}$

\section{Conclusions}

Variations between studies in the observed cystic frequencies may be due to differences in the sample sizes as well as inter- and intra-observer variations among practitioners during data recording, which

\section{References}

1. Nuñez-Urrutia S, Figueiredo R, Gay-Escoda C. Retrospective clinicopathological study of 418 odontogenic cysts. Med Oral Patol Oral Cir Bucal. 2010 Sep 1;15(5):e767-73.

2. Ochsenius G, Escobar E, Godoy L, Peñafiel C. Odontogenic cysts: analysis of 2,944 cases in Chile. Med Oral Patol Oral Cir Bucal. 2007 Mar 1;12(2):e85-91.

3. Kramer IRH, Pindnorg JJ, Shear M, editors. WHO International histological classification of tumors: histological typing of odontogenic tumors. 2nd ed. Berlin (Germany): SpringerVerlag; $1992.118 \mathrm{p}$.

4. Mosqueda-Taylor A, Irigoyen-Camacho ME, Diaz-Franco MA, Torres-Tejero MA. Odontogenic cysts: analysis of 856 cases. Med Oral. 2002 Mar-Apr;7(2):89-96.

5. Ledesma-Montes C, Hernández-Guerrero JC, Garcés-Ortíz M. Clinico-pathologic study of odontogenic cysts in a Mexican sample population. Arch Med Res. 2000 Jul-Aug;31(4):373-6.

6. Prockt AP, Schebela CR, Maito FD, Sant'Ana-Filho M, Rados PV. Odontogenic cysts: analysis of 680 cases in Brazil. Head Neck Pathol. 2008 Sep;2(3):150-6. Epub 2008 Jun 10.

7. Meningaud JP, Oprean N, Pitak-Arnnop P, Bertrand JC. Odontogenic cysts: a clinical study of 695 cases. J Oral Sci. 2006 Jun;48(2):59-62.

8. Koseoglu BG, Atalay B, Erdem MA. Odontogenic cysts: a clinical study of 90 cases. J Oral Sci. 2004 Dec;46(4):253-7.

9. Varinauskas V, Gervickas A, Kavoliūniene O. Analysis of odontogenic cysts of the jaws. Medicina (Kaunas). 2006;42(3):2017.

10. Jones AV, Craig GT, Franklin CD. Range and demographics of odontogenic cysts diagnosed in a UK population over a 30-year period. J Oral Pathol Med. 2006 Sep;35(8):500-7. could have impaired the histopathological diagnosis and accuracy of the retrospective studies. A definitive diagnosis of the cyst type can be made on the basis of a delicate balance between the clinical, radiological, and histological findings. Accordingly, a strong interdepartmental relationship between the clinician and histopathologist is essential. Knowledge of the clinical and histological behavior of the odontogenic cyst is needed to ensure early detection and prompt treatment of these noncancerous but potentially destructive lesions.

11. Manor E, Kachko L, Puterman BM, Szabo G, Bodner L. Cystic lesions of the jaws - a clinicopathological study of 322 cases and review of the literature. Int J Med Sci. 2012;9(1):20-26.

12. Souza LB, Gordón-Núñez MA, Nonaka CF, de Medeiros MC, Torres TF, Emiliano GB. Odontogenic cysts: demographic profile in a Brazilian population over a 38-year period. Med Oral Patol Oral Cir Bucal. 2010 Jul 1;15(4):e583-90.

13. Tortorici S, Amodio E, Massenti MF, Buzzanca ML, Burruano F, Vitale F. Prevalence and distribution of odontogenic cysts in Sicily: 1986-2005. J Oral Sci. 2008 Mar;50(1):15-8.

14. Avelar RL, Antunes AA, Carvalho RW, Bezerra PG, Oliveira Neto PJ, Andrade ES. Odontogenic cysts: a clinicopathological study of 507 cases. J Oral Sci. 2009 Dec;51(4):581-6.

15. Monteiro L, Peña J, Fonseca L, Paiva A, Amaral B. Odontogenic cysts - a descriptive clinicopathological study. Braz J Oral Sci. Jan-Mar 2005;4(12):670-5.

16. Grossmann SM, Machado VC, Xavier GM, Moura MD, Gomez RS, Aguiar MC, et al. Demographic profile of odontogenic and selected nonodontogenic cysts in a Brazilian population. Oral Surg Oral Med Oral Pathol Oral Radiol Endod. 2007 Dec;104(6):e35-41. Epub 2007 Oct 17.

17. Barnes L, Evenson JW, Reichart P, Sidransky D, editors. World Health Organization classification of tumors: pathology and genetics of head and neck tumors. Lyon (France): IARC Press; 2005.

18. Nxumalo TN, Shear M. Gingival cyst in adults. J Oral Pathol Med. 1992;21(7):309-13.

19. Daley TD, Wysocki GP, Pringle GA. Relative incidence of odontogenic tumors and oral and jaw cysts in a Canadian population. Oral Surg Oral Med Oral Pathol. 1994 Mar;77(3):276-80. 